J. Dairy Sci. 96:7325-7328

http://dx.doi.org/10.3168/jds.2013-6885

(C) American Dairy Science Association ${ }^{\circledR}, 2013$.

\title{
Short communication: Genetic analysis of dairy bull fertility from field data of Brown Swiss cattle
}

\author{
F. Tiezzi, ${ }^{*} \dagger$ C. Maltecca, ${ }^{*}$ M. Penasa, $\dagger^{1}$ A. Cecchinato, $\dagger$ and G. Bittante $\dagger$ \\ *Department of Animal Science, North Carolina State University, Raleigh 27695 \\ †Department of Agronomy, Food, Natural Resources, Animals and Environment, University of Padova, Viale dell'Università 16, \\ 35020 Legnaro (PD), Italy
}

\section{ABSTRACT}

The aim of this study was to estimate heritability and repeatability of dairy bull fertility in Italian Brown Swiss cattle. Bull fertility indicators were calving per service and nonreturn rate at $56 \mathrm{~d}$ after service. Data included 124,206 inseminations carried out by 86 technicians on 28,873 heifers and cows in 1,400 herds. Services were recorded from 1999 to 2008 and were performed with semen from 306 AI Brown Swiss bulls. Data were analyzed with a threshold animal model, which included the fixed effects of parity by class of days in milk of the inseminated cow (age at insemination for heifers), yearseason of insemination, and status of the service bull at the time of insemination (progeny testing or proven), and the random effects of herd, technician, additive genetic, and permanent environment of inseminated heifer/cow and service bull, and residual. Also, genetic covariance between heifer/cow and service bull effects was considered in the model. Heritability and repeatability were 0.0079 and 0.0100 for nonreturn rate at 56 $\mathrm{d}$ after service, and 0.0153 and 0.0202 for calving per service, respectively. The low estimates obtained in the present study indicate that selection for male fertility using field data is hardly pursuable.

Key words: bull fertility, dairy cow, heritability, threshold model

\section{Short Communication}

Traditionally, female fertility has received considerably more attention than its male counterpart, even though evidence exists of the impact of male fertility on the efficiency of the dairy industry (Van Doormaal, 1993; Clay and McDaniel, 2001). Male fertility is mostly characterized by semen fertility, which depends on different factors such as additive and nonadditive genetic effects (Mathevon et al., 1998; Gredler et al., 2007),

Received April 2, 2013.

Accepted July 9, 2013.

${ }^{1}$ Corresponding author: mauro.penasa@unipd.it and a permanent environmental component (Berry et al., 2011).

Heritability (Hyppänen and Juga, 1998; Kuhn and Hutchinson, 2008; Berry et al., 2011) and repeatability (Weigel and Rekaya, 2000; Jamrozik et al., 2005) of bull fertility recorded in field conditions are generally lower than $2 \%$, indicating that several environmental factors exist affecting this trait, which cannot be disentangled in routine collection of field data. Semen parameters assessed in the laboratory are more heritable (Stålhammar et al., 1989), but they are only partially related to field results (Ducrocq and Humblot, 1995; Mathevon et al., 1998; Gredler et al., 2007). To our knowledge, no studies on male fertility in the Brown Swiss breed are currently available. Therefore, the aim of this work was to estimate (co)variance components, heritability, and repeatability of bull fertility in Italian Brown Swiss dairy cattle.

Traits of interest were calving per service (CS) and nonreturn rate at $56 \mathrm{~d}$ after service (NR56). The original data set was obtained from the Breeders Association of Bolzano-Bozen Province (northeast Italy) and consisted of 206,478 single inseminations performed on Brown Swiss heifers and cows from 1999 to 2008. A comprehensive description of the data set has been previously reported by Tiezzi et al. (2011, 2012). Inseminations were validated as successful for CS when gestation length was $288 \pm 15 \mathrm{~d}$ (mean value for Brown Swiss from Norman et al., 2009). If 2 inseminations fell within $288 \pm 15 \mathrm{~d}$, the latter was considered successful. If gestation length of a heifer or a cow was lower than $273 \mathrm{~d}$, the animal was not validated as pregnant. Furthermore, cows having inseminations in a given lactation were required to have recorded inseminations on the previous parity, in such a way that animals with gestation length shorter than $273 \mathrm{~d}$ were not validated as pregnant for that lactation and were eliminated for the subsequent lactations. Nonreturn rate at $56 \mathrm{~d}$ was also calculated for each service, which was validated as nonreturned (NR56 = 1) if no inseminations were performed within $56 \mathrm{~d}$, regardless of whether the nonreturned animal conceived or not. Approximately 30\% 
of inseminations on Brown Swiss population reared in the Alps are conducted using semen of beef bulls to produce crossbred calves for veal and beef production (Dal Zotto et al., 2009; Penasa et al., 2009). However, most of the heifers and the majority of the cows are mated to Brown Swiss bulls. Thus, from the whole set, we extracted inseminations from AI Brown Swiss bulls as service bulls, which represent approximately $70 \%$ of total inseminations. It is necessary to point out that semen used for insemination has gone through strict quality control and this could reduce the differences in fertility among the approved batches of semen from AI bulls. Fertility traits (CS and NR56) were calculated for each service before the extraction of Brown Swiss bulls from the initial data set. Service bulls were required to have at least 100 inseminations, and each herd and technician were required to have at least 20 inseminations. Service bulls, herds, technicians, and sires of heifers/cows with an average CS and NR56 outside the range 0.10 to 0.90 were omitted from the analysis, as it is unlikely that a service bull had less than $10 \%$ or more than $90 \%$ of success on a minimum of 100 inseminations. After editing, 124,206 single inseminations performed by 86 technicians on 28,873 heifers and cows (progeny of 514 sires) in 1,400 herds were available for statistical analysis. There were 306 service bulls that had 406 inseminations, on average, with a minimum of 100 and a maximum of 8,255 inseminations (Table 1 ). The pedigree file included 71,349 individuals.

The threshold animal model used for the estimation of variance components accounted for fixed effects of parity by DIM of the inseminated cow or age at insemination for heifers, year-season of insemination (40 levels), and status of the service bull at the time of insemination (2 levels: progeny testing or proven). Classes of parity by DIM of inseminated cows or age at insemination for heifers were included to account for

Table 1. Description of the data set used (1999 to 2008)

\begin{tabular}{lc}
\hline Item & Value \\
\hline Number of inseminations & 124,206 \\
Average calving per service (CS) & 0.48 \\
Average nonreturn rate at 56 d after service (NR56) & 0.70 \\
Percentage of discordant values & 22 \\
Number of service bulls & 306 \\
Minimum number of inseminations per service bull & 100 \\
Average number of inseminations per service bull & 406 \\
Mean of average CS per service bull & 0.45 \\
Mean of average NR56 per service bull & 0.69 \\
Number of cows & 28,873 \\
Number of sires of cow & 514 \\
Minimum number of inseminations per sire of cow & 20 \\
Number of herds & 1,400 \\
Minimum number of inseminations per herd & 20 \\
Number of technicians & 86 \\
Minimum number of inseminations per technician & 25 \\
\hline
\end{tabular}

the effect of metabolic status of the animal on the outcome of the single insemination, and they were defined as follows: heifers: 366 to 587 d for class 1, 588 to 638 d for class 2, 639 to $689 \mathrm{~d}$ for class 3,690 to $740 \mathrm{~d}$ for class 4, 741 to $792 \mathrm{~d}$ for class 5 , and 793 to $1,000 \mathrm{~d}$ for class 6; cows: 4 classes of parity (first, second, third, and fourth and later) and 5 classes of DIM (21 to $63 \mathrm{~d}$ for class 1,64 to $84 \mathrm{~d}$ for class 2,85 to $105 \mathrm{~d}$ for class 3, 106 to $147 \mathrm{~d}$ for class 4 , and 148 to $357 \mathrm{~d}$ for class $5)$. This categorization led to 26 different levels. Besides the aforementioned fixed factors, the model accounted for random effects of herd, technician, additive genetic, and permanent environment of bred heifer/cow and service bull, and residual term. Moreover, genetic covariance between the inseminated heifer/cow and service bull was taken into account, fitting the service bull and sire of cow additive genetic effects linked by a common numerator relationship matrix.

All the computations were performed using Bayesian framework via Gibbs sampling algorithm implemented in the software TM (http://snp.toulouse.inra. $\mathrm{fr} / \sim$ alegarra/manualtm.pdf). Default assumptions were bounded uniform priors for fixed effects and variance components, and multivariate normal distributions for random effects. A total of 550,000 iterations were run with the first 50,000 discarded as burn-in. Thinning occurred every 50 iterations and 10,000 samples from every computation were stored for inferences. Convergence was assessed by visual inspection of trace plots. Heritability of bull fertility was computed as a ratio of additive genetic variance to the sum of all (co)variances estimated in the model. For the respective repeatability, the service bull permanent environmental variance was added to the numerator of the previous ratio. Means and lower and upper bounds of the $95 \%$ highest posterior probability density regions (HPD95) for heritabilities were calculated from the Gibbs samples using the coda package of R (http://cran.r-project.org).

The overall mean for CS and NR56 was 0.48 and 0.70 , respectively (Table 1 ). It indicated that $22 \%$ of data were discordant, giving success for NR56 and failure for CS. Nonreturn rate at $56 \mathrm{~d}$ after service seems to be an early but moderate indicator of reproductive efficiency, if we assume CS to be the trait most closely reflecting the real fertility of the heifer or cow.

Estimates for the (co)variance components, heritabilities, and repeatabilities for NR56 and CS (Table 2) were the means of the posterior distributions for the respective parameters. Residual variance was set to 1 due to its unidentifiability on the liability scale. All estimates were low, reflecting the difficulty of assessing factors associated with male fertility from field data, or the low impact of the random effects included in the analysis on field fertility. 
Table 2. Estimates of (co)variance components, heritability, and repeatability for nonreturn rate at $56 \mathrm{~d}$ after service (NR56) and calving per service (CS) ${ }^{1}$

\begin{tabular}{lccccccr}
\hline & \multicolumn{3}{c}{ NR56 } & & \multicolumn{3}{c}{ CS } \\
\cline { 2 - 3 } \cline { 7 - 8 } Parameter $^{2}$ & Mean & SD & HPD95 & & Mean & SD & \multicolumn{1}{c}{ HPD95 } \\
\hline$\sigma_{\text {ss-gen }}^{2}$ & 0.0087 & 0.0024 & $0.0041 ; 0.0130$ & & 0.0173 & 0.0046 & $0.0081 ; 0.0259$ \\
$\sigma_{\text {cow-gen }}^{2}$ & 0.0210 & 0.0037 & $0.0145 ; 0.0290$ & & 0.0447 & 0.0061 & $0.0335 ; 0.0577$ \\
$\sigma_{\text {ss-cow }}$ & 0.0002 & 0.0021 & $-0.0039 ; 0.0045$ & & -0.0030 & 0.0040 & $-0.0107 ; 0.0048$ \\
$\sigma_{\text {ss-pe }}^{2}$ & 0.0023 & 0.0015 & $0.0002 ; 0.0056$ & & 0.0055 & 0.0029 & $0.0008 ; 0.0117$ \\
$\sigma_{\text {cow-pe }}^{2}$ & 0.0261 & 0.0045 & $0.0169 ; 0.0350$ & & 0.0295 & 0.0059 & $0.0177 ; 0.0410$ \\
$\sigma_{\mathrm{h}}^{2}$ & 0.0323 & 0.0024 & $0.0278 ; 0.0371$ & & 0.0197 & 0.0018 & $0.0163 ; 0.0234$ \\
$\sigma_{\mathrm{t}}^{2}$ & 0.0068 & 0.0016 & $0.0042 ; 0.0105$ & & 0.0097 & 0.0020 & $0.0064 ; 0.0103$ \\
$\sigma_{\mathrm{r}}^{2}$ & 1 & & & & 1 & & \\
$\mathrm{~h}^{2}$ & 0.0079 & 0.0021 & $0.0037 ; 0.0118$ & & 0.0153 & 0.0040 & $0.0072 ; 0.0220$ \\
$\mathrm{r}$ & 0.0100 & 0.0023 & $0.0040 ; 0.0164$ & & 0.0202 & 0.0055 & $0.0083 ; 0.0319$ \\
\hline
\end{tabular}

${ }^{1}$ Estimates are the means of the marginal posterior densities for variance components, heritability, and repeatability; SD is the posterior SD; HPD95 is the highest posterior density region at $95 \%$.

${ }^{2} \sigma_{\text {ss-gen }}^{2}$ is the service bull additive genetic variance; $\sigma_{\text {cow-gen }}^{2}$ is the cow additive genetic variance; $\sigma_{\text {ss-cow }}$ is the service bull-cow additive genetic covariance; $\sigma_{\text {ss-pe }}^{2}$ is the service bull permanent environmental variance; $\sigma_{\text {cow-pe }}^{2}$ is the cow permanent environmental variance; $\sigma_{\mathrm{h}}^{2}$ is the herd variance; $\sigma_{\mathrm{t}}^{2}$ is the technician variance; $\sigma_{\mathrm{r}}^{2}$ is the residual variance; $h^{2}$ is the service bull heritability; $r$ is the service bull repeatability.

Variance components for CS were constantly higher than those for NR56, except for herd component, which was higher for NR56 (Table 2). Additive genetic variance of service bull was much lower than that of inseminated heifer/cow, both for NR56 (0.0087 and 0.0210, respectively) and CS (0.0173 and 0.0447, respectively), probably as a consequence of bull screening for semen quality. The genetic covariance between service bull and inseminated heifer/cow was almost null for NR56 (0.0002), and very low for CS (-0.0030), generating low genetic correlations between these effects, which included 0 in the HPD95 (data not shown). The permanent environmental variance of service bull was lower than the genetic variance ( 0.0023 vs. 0.0087 , and 0.0055 vs. 0.0173 for NR56 and CS, respectively), whereas cow permanent environmental variance was similar to the genetic one for NR56 (0.0261 vs. 0.0210) and smaller for CS (0.0295 vs. 0.0447). Finally, herd variance was higher than technician variance, both for NR56 (0.0323 vs. 0.0068) and CS (0.0197 vs. 0.0097).

The posterior means of heritability and repeatability for CS (0.0153 and 0.0202, respectively) were higher than those obtained for NR56 (0.0079 and 0.0100, respectively), but in all cases estimates were very low (Table 2). These findings are in agreement with those reported by Kuhn and Hutchinson (2008) for the Holstein breed and Berry et al. (2011), who assessed heritabilities below 0.01 for CS for dairy and beef cattle, even though Berry et al. (2011) used a linear model to analyze CS data, which is known to result in lower estimates of heritability. Hyppänen and Juga (1998) reported a heritability of 0.001 for NR56 in Finnish Ayrshire cattle, and Stålhammar et al. (1994) estimated a value of about 0.01 for the same trait in Swedish Red and White and Swedish Friesian cattle; both studies used a linear model to analyze the data. Estimates of service bull repeatability for NR56 from the present study was the same as calculated by Jamrozik et al. (2005) using a linear model on Holstein heifers (0.01), but lower than the value reported by the same authors on multiparous cows (0.02). In contrast, Weigel and Rekaya (2000) reported estimates below 0.01 for Holstein cattle, either with linear and threshold models.

The present study corroborates previous research carried out on other dairy populations about the estimation of heritability and repeatability for male fertility, and fills the lack of knowledge about genetic and environmental variation of male fertility in the Brown Swiss cattle breed. It is likely that the quality screening of semen in AI studs and its subsequent manipulation in terms of spermatozoa concentration might level the differences existing among bulls for semen quality and fertilizing ability. Genetic improvement of male fertility seems hardly feasible.

\section{ACKNOWLEDGMENTS}

The authors thank Trento Province (Italy) for financial support, the Breeders Association of Bolzano-Bozen Province (Italy) for providing field data, the Italian 
Brown Swiss Cattle Breeders Association (ANARB, Verona, Italy) for supplying pedigree information, and the Superbrown Consortium of Bolzano and Trento (Italy) for technical support.

\section{REFERENCES}

Berry, D. P., R. D. Evans, and S. Mc Parland. 2011. Evaluation of bull fertility in dairy and beef cattle using cow field data. Theriogenology $75: 172-181$.

Clay, J. S., and B. T. McDaniel. 2001. Computing mating bull fertility from DHI nonreturn data. J. Dairy Sci. 84:1238-1245.

Dal Zotto, R., M. Penasa, M. De Marchi, M. Cassandro, N. Lopez-Villalobos, and G. Bittante. 2009. Use of crossbreeding with beef bulls in dairy herds: Effect on age, body weight, price, and market value of calves sold at livestock auctions. J. Anim. Sci. 87:3053-3059.

Ducrocq, V., and P. Humblot. 1995. Genetic characteristics and evolution of semen production of young Normande bulls. Livest. Prod. Sci. 41:1-10.

Gredler, B., C. Fuerst, B. Fuerst-Waltl, H. Schwarzenbacher, and J. Sölkner. 2007. Genetic parameters for semen production traits in Austrian dual-purpose Simmental bulls. Reprod. Domest. Anim. 42:326-328.

Hyppänen, K., and J. Juga. 1998. Environmental and genetic effects on the 60-day nonreturn rate in Finnish AI bulls. Interbull Bull. 18:91-98.

Jamrozik, J., J. Fatehi, G. J. Kistemaker, and L. R. Schaeffer. 2005. Estimates of genetic parameters for Canadian Holstein female reproduction traits. J. Dairy Sci. 88:2199-2208.

Kuhn, M. T., and J. L. Hutchinson. 2008. Prediction of dairy bull fertility from field data: Use of multiple services and identifica- tion and utilization of factors affecting bull fertility. J. Dairy Sci. 91:2481-2492

Mathevon, M., M. M. Buhr, and J. C. M. Dekkers. 1998. Environmental, management, and genetic factors affecting semen production in Holstein bulls. J. Dairy Sci. 81:3321-3330.

Norman, H. D., J. R. Wright, M. T. Kuhn, S. M. Hubbard, J. B. Cole, and P. M. VanRaden. 2009. Genetic and environmental factors that affect gestation length in dairy cattle. J. Dairy Sci. 92:2259-2269.

Penasa, M., M. De Marchi, R. Dal Zotto, A. Cecchinato, M. Cassandro, and G. Bittante. 2009. Influence of the sire on market value of Belgian Blue $\times$ Brown Swiss crossbred calves. Ital. J. Anim. Sci. 8(Suppl. 3):113-115.

Stålhammar, E.-M., L. Janson, and J. Philipsson. 1989. Genetic studies on fertility in A.I. bulls. I. Age, season and genetic effects on semen characteristics in young bulls. Anim. Reprod. Sci. 19:1-17.

Stålhammar, E.-M., L. Janson, and J. Philipsson. 1994. Genetic studies on fertility in A.I. bulls. II. Environmental and genetic effects on non-return rates of young bulls. Anim. Reprod. Sci. 34:193-207.

Tiezzi, F., C. Maltecca, A. Cecchinato, M. Penasa, and G. Bittante. 2012. Genetic parameters for fertility of dairy heifers and cows at different parities and relationships with production traits in first lactation. J. Dairy Sci. 95:7355-7362.

Tiezzi, F., C. Maltecca, M. Penasa, A. Cecchinato, Y. M. Chang, and G. Bittante. 2011. Genetic analysis of fertility in the Italian Brown Swiss population using different models and trait definitions. J. Dairy Sci. 94:6162-6172.

Van Doormaal, B. J. 1993. Linear model evaluations of non-return rates for dairy and beef bulls in Canadian AI. Can. J. Anim. Sci. 73:795-804.

Weigel, K. A., and R. Rekaya. 2000. Genetic parameters for reproductive traits of Holstein cattle in California and Minnesota. J. Dairy Sci. $83: 1072-1080$. 